\title{
Gebelikte Bitkisel Ürün Kullanımı
}

\author{
Herbal Products Use in Pregnancy
}

\author{
Arzu KUL UÇTU' ${ }^{1}$, Hediye KARAKOÇ²
}

ÖZ

İlk çağlardan günümüze bitkilerin şifasına inanılmakta, bitki ve özlerinden elde edilen ürünler kullanılmaktadır. Fizyolojik ve psikolojik birçok değişikliğin görüldüğü gebelik döneminde çeşitli semptom veya rahatsızlık yaratan durumların giderilmesinde bitkisel ürünler kullanılabilmektedir. Ancak gebelikte bitkisel ürün kullanımının güvenliliği ve etkilerine ilişkin çalışmalarbulunmasına karşın, henüz fikir birliğine varılamamıştır. Bazı bitkisel ürünlerin kullanımı sonucunda gebelikte teratojenik etkilerinin olabileceği konusunda yeterli bilgi düzeyine erişilemediği vurgulanmaktadır. Gebelikte kullanılan bitkisel ürünlerin fetal mortalite ve morbidite risklerini artırabileceği ifade edilmektedir. Ayrıca bu dönemde reçete edilmiş kullanılması gereken ilaçlarla etkileşime girerek fetal ölüm veya malformasyonlara neden olabilmektedir. Henüz bilimsel açıdan güvenilirliği kanıtlanmamış bitkisel ürün kullanımını önlemek için özellikle bu alanda uzmanlaşmış sağlık profesyonellerinin danışmanlık yapması ve kanıta dayalı bilgiler 1şı̆̆ında daha etkin rol alması gerekmektedir.

Anahtar Kelimeler: Gebelik, Maternal, Fetal, Bitkisel Ürün, Sağlik

\begin{abstract}
Herbs have been believed to heal and products derived from plants and their extracts have been used since the early ages. Herbal products can be used in the elimination of various symptoms or discomforts during the pregnancy period when many physiological and psychological changes are observed. However, although there are studies on the safety and efficacy of using herbal products in pregnancy, no consensus has yet been reached. It is emphasized that the use of certain herbal products does not result in sufficient knowledge about teratogenic effects in pregnancy. It is stated that the herbal products used in pregnancy may increase fetal mortality and morbidity risks. In addition, during this period, it may cause fetal death or malformations by interacting with prescription drugs that should be used. To prevent the use of herbal products that have yet to be scientifically proven to be reliable, health workers need to be consulted and act more effectively in the light of evidencebased information.
\end{abstract}

Keywords: Pregnancy, Maternal, Fetal, Herbal Product, Health

\section{GíRiş}

İlk çağlardan günümüze bitkilerin şifasına inanılmakta, bitki ve özlerinden elde edilen ürünler kullanılmaktadır (1). Teknolojinin ilerlemesi, biyokimya alanında yaşanılan gelişmeler sonucu tıbbi amaçlı kullanılan bitki sayısı giderek artmakta sağlık ürünlerinde bitkisel ürünlerin kullanımı tercih edilmektedir. Bitkisel ürünlerde, bütün, parçalanmış veya kesilmiş bitkiler, bitki parçaları, alg, mantar ve liken gibi türlerin taze, kurutulmuş veya farklı şekilleri kullanılabilmektedir. Bitkisel preparat ise; ekstraksiyon, damitma, ekspresyon, fraksiyonlama, saflaştırma, konsantrasyon veya fermentasyon gibi işlemlerle öğütülmüş, toz halinde veya yağ şeklinde değişik formlarda elde edilen ürünlerdir. Tüm bu ürünler geleneksel bitkisel ürünler olarak adlandırılmaktadır (2). 
Dünya Sağl1k Örgütü (DSÖ) 2015 y1lı raporuna göre; sağlı̆̆1 geliştirmek, hastalıkları önlemek veya tedavi amacıyla insanların yaklaşık yarısından fazlasının çeşitli bitkisel ürünler kullandığ 1 belirtilmektedir (3). Bitkisel ürünlerin satışı ve kullanımı ile ilgili yasal düzenlemelerde yetersizlikler bulunmaktadır. Ancak, bu durum gelişmekte olan ülkelerde yüksek oranlardaki kullanım oranlarını etkilememektedir (4). DSÖ tamamlayıcı ve alternatif tıpta kullanılan uygulamaların baskın sağlık sistemi içerisinde yer alması gerektiğini vurgulamaktadır (5). Bitkisel ürünlerin kullanımını önerecek veya denetleyecek uygulayıcıların eğitimli olması gerekmektedir. Bitkisel ürün kullanımı konusunda uzmanlaşmış bireylerin ulusal düzenlemelere kanıta dayalı çalışmalarla katkı sağlayarak bunları uluslararası platformlarda duyurmalarının önemli olacağı ifade edilmektedir $(1,5,6)$.

\section{Gebelikte Bitkisel Ürün Kullanımı}

Gebelikte stres ve kaygı nedenleri değişmekle birlikte, fetal sağllğa veya sürece ilişkin endişe yaşanabilmektedir. $\mathrm{Bu}$ süreçte stresi azaltmak ve rahatlamak için kullanılabilecek konvansiyonel ilaçların zararlı olduğu ve konvansiyonel tedavinin toplum tarafindan hoş karşılanmadığ 1 düşüncesiyle çoğunlukla bireysel kararlar doğrultusunda bitkisel ürünler kullanıldığı belirtilmektedir (7). Çoğunlukla, bitkisel ürünlerin doğal yollardan tedavi edebileceği görüşü nedeniyle sentetik ilaç kullanımı yerine tercih edildiği vurgulanmaktadır (4). Ancak, gebelikte bitkisel ürün kullanımının güvenliliği ve etkililiğine ilişkin çalışmalar yeterli veri olmaması nedeniyle henüz fikir birliğine varılamamıştır (8-10). Bazı bitkisel ürünlerin gebelikte kullanımı sonucunda aynı ilaçlarda olduğu gibi teratojenik etki olabilir (4). Amerika Birleşik Devletleri Gıda ve İlaç Ajansı (FDA), Avrupa İlaç Ajansı (EMA) ve Alman Komisyon E bitkisel ürünlerin gebelik ve laktasyon döneminde kullanımı ile ilgili yeterli bilimsel veriler olmadığı için kullanılmasını önermemektedir (9).

Gebelikte dönemlere göre rahatsızlık yaşanabilmekte ve etkilenme düzeyleri bireysel farkl1l1klar göstermektedir. Yaşanan fizyolojik süreçlere uyumu arttırmak amacıyla rutin gebelik izlemleri sırasında sunulan bakım ve danışmanlık hizmetleri içerisinde; yaşam tarzı değişiklikleri, doğuma hazırlık eğitimleri, egzersiz eğitimi, vitamin ve mineral desteği, beslenme alışkanlıkları, stresle baş etme yöntemleri ve güvenli ilaç dışı girişimlerin uygulanması yer almalıdır (11). $\mathrm{Bu}$ nedenle gebeliğe özgü stres nedenlerinin belirlenerek çözüme kavuşturulması, gebelerin henüz güvenliliği kanıtlanmamış bitkisel ürünlerde çare arama oranlarının azaltılmasında etkili bir yol olacaktır (12).

Gebeler herhangi bir sağlık personeline danışmadan bitkisel ürün kullanabilmektedir (10). Bu nedenle, gebenin iletişimde bulunabileceği sağlık çalışanlarının bitkisel ürün kullanımına ilişkin etki, istenmeyen etki veya olası riskler hakkında kanıta dayalı bilgi gereksinimini karşılayabiliyor olması önem taşımaktadır. Sağlık profesyonelleri maternal ve fetal sağlığın korunması açısından her bitkisel ürünün güvenli olmayabileceği, etkililiğinin henüz kanıtlanmamış olabileceği ve yaşanabilecek olası sorunlarda kendilerinden destek alınması gerektiği hususunda kadının eğitilmesini sağlamalıdır (13).

\section{Gebelikte Bitki veya Ekstrelerinin Kullanım Sıklığı ve Tercih Nedenleri}

Gebelikte en az bir kez bitkisel ürün kullanımının Amerika ve Avusturalya'da ortalama \%7-45, Çin'de \%30-50 olduğu belirtilmektedir $(8,14)$. Bölgesel farklılıklarla birlikte bazı ülkelerde $\% 80$ 'e varan oranlarda gebelik döneminde bitkisel ürün kullanıldığı bildirilmektedir (15). Fakeye ve ark. (2009) tarafindan bitkisel ürün kullanımını incelemek amacıyla Nijerya'da 599 gebe ile yürütülen bir araştırmada $\% 65,7$ 'sinin farklı formlarda bitkisel ürün kullandığ belirlenmiştir. Gebelerin \%30'u istenmeyen etkisinin bulunmaması, $\% 21,1$ 'i erişimin kolay olması ve $\% 12,5$ ' $i$ kültürel özellikler nedeniyle bitkisel ürünleri tercih ettiğini belirtmiştir (4). Avustralya'da gebelikte hangi bitkisel ürünlerin kullanıldığını araştırmak amacıyla gerçekleştirilen (n:400) bir çalışmaya göre; gebelerin \%71'inin papatya, \%63'ünün kızılcık, \%59'unun ekinezya, \%50'sinin sarımsak, \%42'sinin zencefil, \%22'sinin ahududu yaprağı kullandığ ve ürünlerin çoğunlukla arkadaş ya da aile bireylerinin önerileri doğrultusunda kullanıldığı belirlenmiştir $(4,16)$. Ülkemizde gebelerin bitkisel ürün kullanımını incelemek amaciyla gerçekleştirilen (n:366) bir çalışmada; gebelerin $\% 47,3$ 'ünün gebeliği süresince en az bir kez bitkisel ürün, \%58,7'sinin kimsenin önerisi olmadan, \%25,7'sinin arkadaş veya akraba ve \%13,9'unun sağlık çalışanı önerisi üzerine bitkisel ürün kullandığı belirlenmiştir. Gebelerin birinci ve ikinci üç aylık dönemde (trimestır) soğuk algınlığı ve grip rahatsızlıklarını gidermek amacıyla en sik ıhlamur $(\% 23,2)$, nane-limon $(\% 20,2)$ ve kuşburnu $(\% 6,3)$ kullandığ saptanmıştır (17). Bitkilerin doğal ve sağlıklı olabileceği düşüncesinden hareketle gebelerin oluşabilecek istenmeyen 
etkiler konusunda yeterince bilinçli davranmadıkları ifade edilmektedir (18). Bazı bitkisel ürünlerin gebelik sırasında tüketimi konusunda sorun yaşanmaması tüm bitkilerin güvenle kullanılabileceği sonucunu doğurmamaktadır. Gebelerin bitkisel ürünleri kullanma konusunda istekli oluşlarına ve bilgi eksikliği yaşamalarına karşın, sağlık çalışanlarının bitkisel ürünler ile ilgili yeterince bilgi sahibi olmadığı konusuna dikkat çekilmektedir $(4,16)$.

\section{Gebelikte Bitki veya Ekstre Kullanımı Olası Riskleri}

Gebelik dönemlerine göre bulant1, kusma, fetal iyilik haline ilişkin endişe, yorgunluk, uyku sorunu gibi nedenlerle stres yaşanabilmektedir. Gebelerin stres düzeylerini azaltmak ve sorunlarına çözüm bulmak amacıyla bitkisel ürünlere başvurdukları belirtilmektedir (16). Uyku sorunu yaşayan gebelerin rahatlamak amacıyla sıklıkla tek başına papatya kullanabildikleri gibi ek olarak lavanta veya ballı limon tükettikleri bildirilmektedir $(7,8,16)$. Yorgunluk sorununu çözmek ve enerji düzeyini arttırmak amacıyla ginseng kullandıkları saptanmıştır (16). Matthews ve arkadaşları (2010) tarafından gebelikte bulantı ve kusmanın engellenmesi amaciyla zencefil, papatya, nane yağı, limon yağı ve farmakolojik ajan kullanımlarının değerlendirildiği 5449 gebe ile yürütülen 41 klinik çalışmanın incelendiği meta analizde; gebelikte zencefil, limon yağı, nane yağ ve papatya kullanımının etkililiği ve güvenliliği ile ilişkili kanıt düzeyinin düşük olduğu ve ileri düzey çalışmalara ihtiyaç bulunduğu bildirilmektedir (19). Gestasyonel rahatsızlıkların (bulantı, kusma, kaşıntı vb.) giderilmesi amaciyla muhtemel antikolinerjik, antihistaminik ve antiemetik etkilerinden dolayı sıklıkla zencefil kullanıldığı belirtilmektedir (20). Geleneksel Çin tıbbına göre; zencefil kullanan bir kısım gebenin rahatlama sağlayacağı, diğerlerinin bulantı kusma şikâyetinin alevlenebileceği ve mide yanması problemi yaşayabileceği bunun yerine nane kullanmasının daha uygun olacağı görüşü savunulmaktadır $(6,21,22)$. Birinci Basamak Ulusal İşbirliği Merkezi (NCCPC, Londra) doğum öncesi bakım rehberine göre bulantı kusma şikâyetlerinin azaltılmasında zencefilin güvenle kullanılabileceği belirtilmektedir (23). Gebelikte zencefil kullanımının B6 vitamini kullanımına göre bulantı ve kusma şikâyetleri üzerinde etkinliğinin incelendiği bir çalışmaya göre; B6 vitamini ve zencefil kullanımının kusma şikâyetleri gidermede eşit düzeyde etkili olduğu, zencefilin bulantı şikâyetlerini gidermede B6 vitaminine kıyasla daha anlamlı düzeyde rahatlama sağladığı belirtilmektedir (24).
Bir başka çalışmada da benzer sonuçlar elde edilmiş ve zencefil kullanımı ile görülen istenmeyen etkiler önemsiz ve tedavi gerektirmeyen nitelikte olmuştur(25). Gebeliğin erken dönemlerinde sabah yaşanan bulantı kusma şikâyetlerinin giderilmesinde kullanılan zencefilin etkili olduğuna ilişkin randomize kontrollü çalışmalar bulunmasına karşın $(26,27), 5449$ gebenin şikâyetlerini gidermede zencefil kullanımının etkili ve güvenli kullanımına ilişkin yeterli kanıt bulunamadığı vurgulanmaktadır $(20,28)$. Ekinezya, papatya, kuşburnu gibi çay olarak tüketilebilen bitkilerin soğuk algınlığı gibi sorunlara karşı kullanımı konusunda sağlık profesyonellerinin yardımına gereksinim duymadıkları belirtilmektedir (16).

Gebelerin bitkisel ürünlerin doğal olduğuna dair inanışları, oluşabilecek riskler konusunda yeteri öngörüde bulunmalarını engellemektedir. Gebelikte kullanılan bitkisel ürünlerin fetal mortalite ve morbidite risklerini artırabileceğ $i$ ifade edilmektedir. Ayrıca bu dönemde reçete edilmiş kullanılması gereken ilaçlarla etkileşime girerek fetal ölüm veya malformasyonlara neden olabilmektedir (13). Malezya'da gerçekleştirilen bir vaka-kontrol çalışmasına göre; birinci trimesterde kullanılan geleneksel olarak bitki karışımıyla elde edilen ürünlerin kullanımı ile prenatal mortalite arasında anlamlı ilişki bulunduğu belirtilmektedir. Ayrıca, özellikle gebeliğin ilk zamanlarında kullanılan içeriği tanımlanmamış bitkisel karışımların prenatal mortalite riskini arttırdığı, gebeliğin son aylarında kullanılan hindistan cevizi yağının prenatal mortalite oranlarını azalttığı ifade edilmektedir (29). Bitkisel ürünlerin sıvı halde hazırlanması sırasında alkol kullanılabildiği, alkol dozuna bağlı olarak fetal alkol sendromuna sebep olabileceği olası riskler arasında yer almaktadır $(30,31)$.

\section{SONUÇ VE ÖNERILER}

Gebelik döneminde bitkisel ürün kullanım oranının yüksek olmasına karşın bitkisel ürünlerin maternal ve fetal sağlık üzerine etkileri ile ilgili yeterince bilimsel veri bulunmamaktadır. Bitkisel ürünlerin doğal ve zararsız olduğu görüşüyle gebelik döneminde yaşanan rahatsızlıklara bitkisel çözüm arayışının gebelik kayıplarına ve malformasyonlara neden olabileceği düşünülmektedir. $\mathrm{Bu}$ nedenle özellikle prekonsepsiyonel dönemde henüz bilimsel açıdan güvenilirliği kanıtlanmamış bitkisel ürün kullanımını önlemek için bu alanda uzmanlaşmış sağlık profesyonellerinin danışmanlık yapması ve kanıta dayalı bilgiler ışığında daha etkin rol alması gerekmektedir. 


\section{KAYNAKLAR}

1. Faydaoğlu E, Sürücüoğlu MS. Geçmişten günümüze tıbbi ve aromatik bitkilerin kullanılması ve ekonomik önemi. Kastamonu Üniversitesi Orman Fakültesi Dergisi. 2011;11(1):52-67.

2. Vlietinck A, Pieters L, Apers S. Legal requirements for the quality of herbal substances and herbal preparations for the manufacturing of herbal medicinal products in the European Union. Planta Medica. 2009;75(07):683-8.

3. Burton A, Smith M, Falkenberg T. Building WHO's global strategy for traditional medicine. European Journal of Integrative Medicine. 2015;7(1):13-5.

4. Fakeye TO, Adisa R, Musa IE. Attitude and use of herbal medicines among pregnant women in Nigeria. BMC Complementary and alternative medicine. 2009;9(1):53.

5. WHO. WHO traditional medicine strategy 2014-2023. World Health Organization. 2013.

6. Pallivalappila AR, Stewart D, Shetty A, Pande B, Singh R, Mclay JS. Complementary and alternative medicine use during early pregnancy. European Journal of Obstetrics and Gynecology and Reproductive Biology. 2014;181:251-5.

7. Matsui D. Adherence with drug therapy in pregnancy. Obstetrics and gynecology international. 2012;2012.

8. Forster DA, Denning A, Wills G, Bolger M, McCarthy E. Herbal medicine use during pregnancy in a group of Australian women. BMC pregnancy and childbirth. 2006;6(1):21.

9. John LJ, Shantakumari N. Herbal medicines use during pregnancy: a review from the Middle East. Oman medical journal. 2015;30(4):229.

10. Dog TL. The use of botanicals during pregnancy and lactation. Alternative Therapies in Health and Medicine. 2009;15(1):54.

11. Organization WH. WHO recommendations on antenatal care for a positive pregnancy experience: World Health Organization; 2016.

12. Skouteris H, Wertheim EH, Rallis S, Milgrom J, Paxton SJ. Depression and anxiety through pregnancy and the early postpartum: an examination of prospective relationships. Journal of affective disorders. 2009;113(3):303-8.

13. Kim Sooi L, Lean Keng S. Herbal medicines: Malaysian women's knowledge and practice. Evidence-Based Complementary and Alternative Medicine. 2013;2013.

14. Gibson PS, Powrie R, Star J. Herbal and alternative medicine use during pregnancy: a cross-sectional survey. Obstetrics \& Gynecology. 2001;97(4):S44-S5.

15. Kamatenesi-Mugisha M, Oryem-Origa H. Medicinal plants used to induce labour during childbirth in western Uganda. Journal of ethnopharmacology. 2007;109(1):1-9.

16. Nordeng $\mathrm{H}$, Havnen GC. Use of herbal drugs in pregnancy: a survey among 400 Norwegian women. Pharmacoepidemiology and drug safety. 2004;13(6):371-80.
17. Kıssal A, Güner ÜÇ, Ertürk DB. Use of herbal product among pregnant women in Turkey. Complementary therapies in medicine. 2017;30:54-60.

18. Duru CB, Uwakwe KA, Chinomnso NC, Mbachi II, Diwe $\mathrm{KC}$, Agunwa CC, et al. Socio-demographic determinants of herbal medicine use in pregnancy among Nigerian women attending clinics in a tertiary Hospital in Imo State, southeast, Nigeria. Am J Med Stud. 2016;4(1):1-10.

19. Matthews A, Dowswell T, Haas DM, Doyle M, O'Mathuna DP. Interventions for nausea and vomiting in early pregnancy. Cochrane Database Syst Rev. 2010;9.

20. Matthews A, Haas DM, O'Mathúna DP, Dowswell T. Interventions for nausea and vomiting in early pregnancy. Cochrane Database of Systematic Reviews. 2015(9).

21. Bishop JL, Northstone K, Green J, Thompson EA. The use of complementary and alternative medicine in pregnancy: data from the Avon Longitudinal Study of Parents and Children (ALSPAC). Complementary therapies in medicine. 2011;19(6):303-10.

22. Wilkinson JM. What do we know about herbal morning sickness treatments? A literature survey. Midwifery. 2000;16(3):224-8.

23. NCCPC. Antenatal care: routine care for the healthy pregnant woman: RCOG press; 2008.

24. Ensiyeh J, Sakineh M-AC. Comparing ginger and vitamin B6 for the treatment of nausea and vomiting in pregnancy: a randomised controlled trial. Midwifery. 2009;25(6):649-53.

25. Chittumma $\mathrm{P}$, Kaewkiattikun $\mathrm{K}$, Wiriyasiriwach $\mathrm{B}$. Comparison of the effectiveness of ginger and vitamin B6 for treatment of nausea and vomiting in early pregnancy: a randomized double-blind controlled trial. Journal-medical association of thailand. 2007;90(1):15.

26. Ozgoli G, Goli M, Simbar M. Effects of ginger capsules on pregnancy, nausea, and vomiting. The Journal of Alternative and Complementary Medicine. 2009;15(3):243-6.

27. Viljoen E, Visser J, Koen N, Musekiwa A. A systematic review and meta-analysis of the effect and safety of ginger in the treatment of pregnancy-associated nausea and vomiting. Nutrition journal. 2014;13(1):20.

28. Stanisiere J, Mousset P-Y, Lafay S. How safe is ginger rhizome for decreasing nausea and vomiting in women during early pregnancy? Foods. 2018;7(4):50.

29. Ab Rahman A, Ahmad Z, Naing L, Sulaiman SA, Hamid AM, Daud WNW. The use of herbal medicines during pregnancy and perinatal mortality in Tumpat District, Kelantan, Malaysia. Southeast Asian Journal of Tropical Medicine and Public Health. 2007;38(6):1150.

30. Tiran D. The use of herbs by pregnant and childbearing women: a risk-benefit assessment. Complementary Therapies in Nursing and Midwifery. 2003;9(4):176-81.

31. Pradeepkumar V, Tan K, Ivy N. Is 'Herbal Health Tonic'Safe in Pregnancy; Fetal Alcohol Syndrome Revisited. Australian and New Zealand journal of obstetrics and gynaecology. 1996;36(4):420-3. 